\title{
Simulated physical ageing: A prioritized persona-based model for accessible interiors in senior housing environments
}

Indoor and Built Environment 0(0) 1-16

(C) The Author(s) 2020

Article reuse guidelines:

sagepub.com/journals-

permissions

DOI: 10.1177/1420326X20952817 journals.sagepub.com/home/ibe

(S)AGE

\author{
Şevkiye Merve Taşoz $\mathbb{D}$ and Yasemin Afacan
}

\begin{abstract}
Accessibility is a critical interior design consideration that increases performance level and allows older adults to be independent and physically active in their daily activities. This study used a case study to present a new method of combining ageing simulation with personas through importance-performance analysis (IPA) and supporting the basic activities of daily living (BADL). This study developed a prioritized persona-based (PP-B) model to create accessible interiors in senior housing environments for healthy ageing. This model was constructed based on an ontology framework. The data that was gathered through the self-assessment accessibility questionnaire by 60 older adults and it was depicted in the IPA matrix, which later translated into personas. These personas were simulated with an ageing suit by interior architecture students based on the BADL of accessible senior housing environments. This study was an initial attempt to deal with the complex nature of accessible interior design and its attributes for ageing studies, which are often considered as theoretical concepts and standards. The main innovation of this developed PP-B model was to synchronize interior design knowledge on accessibility attributes and users BADL performance along their accessibility importance rankings. Findings are beneficial for interior designers to make human-centred interior design decisions.
\end{abstract}

\section{Keywords}

Accessibility, Human-centred design, Persona, Simulated ageing, Basic activities of daily living, Ontology

Accepted: 2 August 2020

\section{Introduction}

Population ageing is a worldwide phenomenon that is characterized by an increasing number of people who are aged 60 years or older. ${ }^{1,2}$ To remain active as a part of growing old is important for the well-being, and this is also a crucial aspect for the holistic health of the society. ${ }^{3,4}$ Empirical studies show that the relationship between older adults and the design of their interior environment is significant for healthy ageing. ${ }^{5}$ Healthy ageing is 'the process of developing and maintaining the functional ability that enables well-being in old age'. 6

There is strong scientific evidence that regular physical activity results in major and extensive health benefits for adults aged 65 and older. ${ }^{7}$ Basic activities of daily living (BADL) are considered as the basic content of a successful and healthy life. ${ }^{8}$ Thus, it is essential to have equitable access without restrictions in one's BADL. ' Within this context, accessibility is a critical interior design consideration that allows older

Interior Architecture and Environmental Design, Bilkent University, Ankara, Turkey

\section{Corresponding author:}

Şevkiye Merve Taşoz, Faculty of Art, Design and Architecture, Department of Interior Architecture \& Environmental Design, Bilkent University, Ankara 06800, Turkey.

Email: sevkiye.kaya@bilkent.edu.tr 
adults to be independent and physically active in their daily activities. ${ }^{5}$ However, inaccessibility in buildings is a common obstacle that older adults encounter and can present barriers to their ability to participate in daily living activities. ${ }^{10,11}$ So, to achieve healthy ageing, it is crucial to promote physical activity and interior accessibility through human-centred design (HCD) considerations in housing environments. ${ }^{7}$ Although there are a lot of studies on accessible housing environments, designers are still struggling to have empathy for older adults in regards to their physical activity patterns. ${ }^{12}$ As a result, the accessibility of housing environments should be studied from older adults' perspectives with a focus on efficient ranking methods and specialized unique empathy techniques. ${ }^{13}$ This study used a case study to demonstrate a new method of combining ageing simulation with personas through importanceperformance analysis (IPA). The reasoning behind the particular combination of these techniques is to overcome the major challenges of interior accessibility and the complex nature of considering human differences and conflicting needs simultaneously. The idea of combining quantitative personas with simulations could overcome the insufficiency of qualitative personas for more extreme situations. Qualitative personas are lacking the systematic and quantitative coding of the right type user information, so that validation and accuracy of the target users become questionable. ${ }^{12}$ Designers would gain a deeper understanding of older adults' real lives if a structured set of information on their prioritized activities of daily living were provided. This study further developed a prioritized persona-based (PP-B) model to create accessible interiors in senior housing environments. Within the framework of the study, prioritized means 'ranked by the users according to the importance and performance attributes to select appropriate sets, resolve conflicts between alternatives and evaluate alternative solutions'. The PP-B model was constructed based on an ontology framework. Figure 1 illustrates the components of this new method.

\section{Use of Personas}

In the contemporary design world, human centredness is a core quality of design. HCD is a group of methods and principles that aims to allow useful, usable, pleasurable and meaningful products, services or building environments for user groups. ${ }^{13}$ When healthy ageing is considered within the framework of HCD, older adults should be encouraged to participate in real life actions. Older adults might be people, who have discernable impairments, but have a strong ambition to remain independent and to contribute to the community. ${ }^{14}$ Furthermore, it is a crucial aspect for our future to provide environments that are usable to the greatest

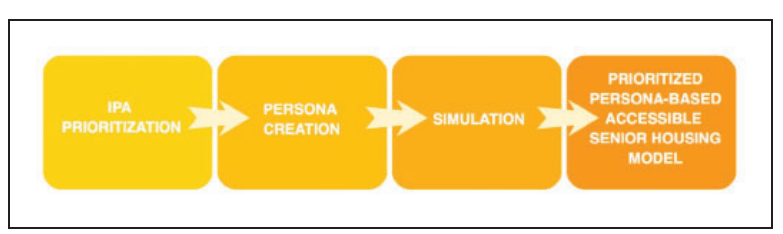

Figure 1. The components of the new method presented in this study.

number of individuals, regardless of their functional abilities. ${ }^{15}$ However, older adults are usually excluded and precluded by inappropriate design issues. ${ }^{16} \mathrm{HCD}$ approach could play an important part in enabling older adults to remain physically and mentally active and independent. The main principle of HCD is to describe how to gain and apply knowledge about human beings and their interaction with their environments and to design products or services that meet target user group's needs and expectations. So, especially in the last decade because of the growing population of older adults and disabled people, there is a significant need for products, services and environments to be developed in a holistic way that they do not exclude, but instead reflect more accurately the variety of demands of today's users. ${ }^{14}$ There are moral, sustainable, professional and economic reasons why designers should be aware of a HCD approach. Morally, designers as a part of the society should be seeking to remove barriers and obstacles that create disabling environments. From a sustainable point of view, there is a strong argument to create communities that encourage participation regardless of age, gender or circumstance. ${ }^{17} \mathrm{HCD}$ argues that increasing numbers of people able to use the design expands the market share and increases business profitability. ${ }^{17}$

Persona is a human-centred design (HCD) method and a persona is an effective method in HCD studies. ${ }^{18}$ The verdict of 'personas' was created by Allan Cooper in $1999 .{ }^{19}$ 'Personas are fictitious, specific, concrete representations of target users. Personas put a face on the user; a memorable, engaging and actionable image that serves as a design target. ${ }^{20}$ Personas provide a better focus on the target user group during the development process of the design or product. ${ }^{21}$ In persona methodology, personas that are created to represent real target user group is described in narrative form for to make persona seem like a real person and to provide a strong story that reflects the needs, expectations and desires of real target users so that designers could focus on the product accordingly. ${ }^{22}$ Nielsen $^{23}$ introduced a 10-step process for persona creation as a guide to overcome the lack of consensus about persona application among designers. By the use of persona method, after development process the need for making changes will be 
reduced and this will consume time for the designers and design groups. ${ }^{19}$ With this approach, an end product will be capable of being used by users with the widest possible range of abilities, needs, desires, and expectations. ${ }^{24}$ Another significant benefit of using personas in the context of design is that personas help one design iteratively so a product or a design can be prototyped, designed, evaluated, and revised through real user research based on a cyclic process. Although persona use was considered as a useful method in HCD field because of its various benefits, in interior architecture and environmental design context, the use of personas for HCD is not common; so it is a unique aspect to use personas as a HCD technique in this specific context.

Goodman-Deane et al. $^{25}$ defined three essential characteristics of personas for assessing inclusivity in a quantitative manner. First, the right type of information should be coded systematically to analyse whether each persona would be able to use the product, service or design efficiently. The second characteristic takes into account how many people are represented by each persona. The third characteristic is whether the target population is represented with sufficient accuracy. ${ }^{25}$ If the persona number is too large, then doing an assessment through these personas becomes unmanageable. Once suitable personas are created, they are asked to evaluate context-specific tasks. Later, the personas' capabilities are compared with the demands of the task steps in order to understand whether they would be able to complete the tasks. ${ }^{22}$ If a persona cannot complete a related task, it means that the group this persona represents will not be able to complete that task either. This study was also built on this particular study because it addressed the user capability data within a set of quantitative personas as a first time, and validated its success with the level of accuracy about user capabilities.

Various studies have provided a set of persona profiles for HCD. However, there are few studies on personas that provide a set of information on capabilities and the activities of daily living. ${ }^{25}$ This study had particular focus on capabilities because of the following reasons: (1) being less studied component of both accessibility and persona sets, (2) being closely related with the happiness and higher degree of independence in activities of daily living (ADL). According to Iwarsson and Stahl, ${ }^{26}$ accessibility is based on two components: (i) the personal component or an individual's functional capacity, (ii) the environmental component or the barriers in relation to available standards. Although accessibility standards as the second component have been studied a lot in the design literature, ${ }^{26}$ the first component, capabilities are in the form of indicators derived from numerical values of human considerations (lacking information on quantitative data or data), which correlate the importance, performance and satisfaction ratings of older adults. ${ }^{27}$ With regards to the second reason, research has revealed that assessment of the functional state of older adults is mainly based on the capability performance of BADL. ${ }^{28}$ Therefore, questions arise as to how one can create personas based on the interior physical performance of older users or provide information on their BADL within the context of the healthy ageing process. A critical perspective is essential while focusing on capability data with persona method. In this context, qualitative personas are insufficient because there is little consensus over exactly how the set of personas cover the entire population taking into account a range of capabilities and specific usability assessments, particularly problematic BADL. ${ }^{25}$ Although quantitative personas have limitations, such as difficulty in conducting and managing the numbers, they are more effective in terms of presenting appropriate information content, convincing number-oriented stakeholders based on quantitative basis and estimating representativeness. This study was an initial attempt to create quantitative personas in order to deal with the complex nature of accessible interior design and its capability attributes, which are often considered theoretical concepts and standards. A major challenge in accessible design is the difficulty that comes with considering these human differences and conflicting claims. ${ }^{27}$ Accessible design is potentially achievable if overall usability for the worst off is maximized ${ }^{13}$ (p. 62). The complexity of accessibility in interior design lies in this paradox. Thus, this study simulated the personas to make better assumptions about target user groups, enhance identification with the user group, and reduce the need for making changes after the design development process.

\section{Empathic design: simulated physical ageing for healthy ageing}

In the design literature, personas are mostly deployed to invoke empathy with user perspectives. ${ }^{21}$ Through the years, several design approaches have emerged to support persona method in user-friendly products and environments such as universal design, inclusive design, trans-generational design, and $\mathrm{HCD} .{ }^{29}$ Among the approaches, empathic design is a design approach that ensures a creative consciousness for specific target users and their daily lives. ${ }^{30}$ It also enables designers to feel for the users in consideration of their special needs. ${ }^{30}$ Pastalan $^{31}$ pioneered an empathic model in the early 1970s. This model places more emphasis on the users of the designed spaces. ${ }^{31}$ Over the years, empathic design has been a valuable response of design for user experience in the way of understanding users and their needs. ${ }^{30}$ There are four principles 
for this approach: (i) balancing rationality and emotions, (ii) making inferences about users and their possible futures through empathy, (iii) involving users in the design process, and (iv) having multi-disciplinary evaluators in the design team. ${ }^{30}$ To be able to design for older adults, designers should experience the world as older adults do. Also, they should be able to gain empathy by the help of knowledge that is constructed by using persona data. ${ }^{32}$

Simulations are often used to achieve the requirements of empathic design. The concept of simulated ageing is relatively new. The suit has been used primarily by the automotive industry to improve vehicle design for older drivers and later it has also been used in medical studies. ${ }^{33}$ Nevertheless, research related to age simulation suits in the field of interior design is very rare. With the help of this age simulation suit, even younger people have the opportunity to experience the physical limitations of older adults (including the loss of vision, hearing, head mobility, grip ability, coordination skills and strength, as well as joint stiffness). On the other hand, there are some limitations to simulations. How the simulations are deployed could result in an over-identification. ${ }^{34}$ It means that while designers are establishing an affective and sensory connection to users, they can represent themselves more representative of other people leading stereotypical ideas about them. This criticism has been in this study as a challenge, and dealt with by combining simulations with quantitative persona method.

\section{Methodology}

\section{Sampling and setting}

A total of 60 Turkish older adults aged 75 and over participated in the study voluntarily, with a mean age of 81.6. The average length of time that each participant had been living in the selected senior housing was over one year to ensure that they represented a broad range of views. All participants were independent in the BADL according to the Barthel Index,${ }^{35}$ and they were not indicative of depression according to the Geriatric Depression Scale (GDS). ${ }^{36}$ The University Institutional Ethical Review Board approved the study. First, the participants, (who were informed about the purposes of the study, their involvement, risks and emergency procedures), signed the informed consent. After they signed, they were enrolled in the study. They were also informed about the confidentiality of the study and their right to terminate their participation in the study at any time.

The case setting was KASEV senior housing for retired teachers. It is a popular senior housing environment in Istanbul, Turkey and it was established in 1986 as a civil society organization. It has the aim of providing healthcare and social services for older adults who are healthy and who are in need of healthcare. KASEV senior housing was chosen for this study for the following reasons: First, as reported by the managers of the senior housing, all the physical and social services of KASEV senior housing are based on an inclusive philosophy that all people should age well (happily and healthily), no matter what age they are. Second, in Turkey, in 2008, the International certificate of ISO in the area of care for older adults is only given to KASEV.

\section{Data collection}

The study has three data collection instruments. A selfassessment questionnaire instrument was developed for the IPA of self-rated accessibility. This instrument has four main parts. The first part (Part A) is about the demographic data. The second part (Part B) includes five structured questions based on a five-point Likert scale, where participants rated (i) their overall accessibility satisfaction with the senior housing; (ii) their importance level in regards to accessibility in general in senior housing; (iii) the current senior housing and their overall independency levels; (iv) their independency level rating on daily living activities in the senior housing; and (v) the most accessible part of the senior housing. This part included two open-ended questions to gather data about their ideas and suggestions related to the relationship between healthy ageing and accessibility. The third part (Part C) and the fourth part (Part D) of the survey were constructed based on Afacan's ${ }^{37}$ study. This study considers first IPA self-assessment questionnaire based on the housing accessibility literature. ${ }^{37}$ In this study, Parts C and D are composed of the same 35 items; they were grouped according to the modified Barthel Index and its association with the following architectural spaces of senior housing: entrances, vertical circulation systems, bathrooms and toilets, dining halls and common living rooms (see Appendices 1 and 2 for the simplified version of the instrument with necessary question that were critical for the discussion). In the Barthel Index, there are 10 BADL items. ${ }^{35}$ This study used an adapted version of the Barthel Index with the following eight items: feeding, dressing, ascending/descending stairs, bathing, getting on/off the toilet, mobility, transfer and personal grooming. Moreover, these eight items were later converted to five architectural space categories, such as: (i) walking: mobility in between interior spaces, (ii) bathing and toilet usage, (iii) feeding: eating and drinking, (iv) personal care and dressing, and (v) transfer: movement without balance lost. In Part C, the participants rated their importance level of these 35 accessibility 
importance items under these five categories, on a 5 -grade scale, from 1 (least important) to 5 (most important) to identify the importance rankings of accessibility items in senior housing. Part D was composed of the same 35 questions, but the participants were asked to rate their own senior housing accessibility performance levels for each item on the same 5grade scale, from 1 (very dissatisfied) to 5 (very satisfied). The survey participants were given the definition of satisfaction; this term indicates the degree to which they are satisfied with their ability to access and then carry out the designated function. All the questions were translated into Turkish and checked by two native Turkish proof-readers, followed by the interviewers' training and pilot studies. The four highly skilled interviewers conducted face-to-face interviews. Interviewers collected the data during senior housing visits. Moreover, the interviewers took photographs of each senior home environment for more in-depth analyses. The survey data was collected face-to-face, in a place that was convenient for the participants in the senior housing to access.

The second data collection tool was The GERontologic Test (GERT) age simulation suit. It enables young subjects to experience the physical limitations of older adults with respect to vision, audition, mobility, balance, grip ability and strength. ${ }^{38}$ It gives the young subjects the opportunity to have a better understanding of older adults' behaviours. The four separate main components, including: (i) age simulation head, (ii) age simulation torso, (iii) age simulation legs and (iv) age simulation arms. The age simulation head also consists of special polycarbonate glasses that cause changes in colour perception, grainy blurring, glare sensitivity and narrowed visual perception and hearing protectors that cause high frequency hearing loss.

The third data collection instrument was the task scenarios. Five task scenarios were developed: (i) mobility tasks, (ii) personal care tasks, (iii) bathroom tasks, (iv) dining tasks and (v) transfer tasks. A chronometer measured the performance of the participants in task scenarios in seconds. All scenarios were conducted with the GERT suit and without the GERT suit. Table 1 illustrates the tasks and sub-tasks.

Six volunteer evaluators (with the mean age of 24.5) were chosen from fourth-grade interior architecture students. They were considered as future designers. All the evaluators were in the same fit body index and were in this senior housing for the first time. None of the evaluators had tried a GERT suit before this study. Three of the evaluators were females and the other three of them were males (to order to avoid any biases). Moreover, all of the evaluators had background knowledge and consciousness about ageing- related studies and the HCD approach. In order to measure the perceived closeness between the evaluators and older adults, one question was asked in the Inclusion of Other in the Self (IOS) Scale by Aron, Aron and Smollan. ${ }^{39}$ The IOS scale aims to help to understand the perception of the evaluators (i.e. how close they feel with older adults). ${ }^{39}$

\section{Data analysis}

The first author conducted the data analysis. The study was composed of four stages of data analysis. The first stage was IPA and prioritization. IPA is one of the most commonly used methodological tools in tourism literature in the context of setting priorities on two dimensions: importance and performance. IPA has been used for years in a variety of settings, especially in tourism research ${ }^{40}$ and healthcare research. ${ }^{41}$ Afacan ${ }^{37}$ suggested that IPA was an effective tool in deciding how to best meet housing accessibility requirements for older adults in order to maximize their ability to access home elements and carry out daily activities. Martilla and James ${ }^{42}$ originally introduced IPA. The aim of IPA is to achieve customer satisfaction by providing customer insights into service attributes. ${ }^{42}$ Data from customer surveys is depicted in a two-dimensional matrix. In the matrix, the $\mathrm{x}$-axis depicts attribute importance and the y-axis depicts attribute performance. The attribute weights are derived from regression weights, structural equation models, correlation weights, etc. These means of importance and performance divide the matrix into four quadrants. The first quadrant includes attributes with high importance and performance, which refers to the key qualities in sustaining a competitive advantage. ${ }^{43}$ In the second quadrant, there are attributes with high importance but low performance, which signify that they need immediate attention. ${ }^{42}$ Quadrant three includes attributes of low importance and performance; it is therefore not necessary to put in additional effort with these attributes. Quadrant four is rated as low importance but high performance, which implies that resources for these attributes could be used elsewhere.

In the study, importance and performance data were plotted against one another on a two dimensional grid. According to IPA, one should take mean values into consideration before creating an IPA matrix. Mean values under 1.5 (including 1.5) and values above 4.5 (including 4.5) were not analysed due to the "floor and ceiling effect'. Later, the overall mean values of performance defined the origin for the $y$-axis and the overall mean values of importance defined the origin for the $x$ axis. As a result, four quadrants existed and the related data was distributed into one of four quadrants: 'Keep 
Table 1. Tasks that will be done with and without the GERT simulation suit.

\begin{tabular}{|c|c|c|c|c|}
\hline Mobility Tasks (MT) & $\begin{array}{l}\text { Personal Care Tasks } \\
(\mathrm{PCT})\end{array}$ & Bathroom Tasks (BT) & $\begin{array}{l}\text { Dining Tasks } \\
\text { (DT) }\end{array}$ & Transfer Tasks (TT) \\
\hline $\begin{array}{l}\text { MT1: Walking from } \\
\text { parking lot to } \\
\text { entrance (lobby) } \\
\text { area. }\end{array}$ & $\begin{array}{l}\text { PCT1: Wearing a } \\
\text { sweater and button } \\
\text { up. }\end{array}$ & BT1: Access to sink. & $\begin{array}{l}\text { DT1: Drinking a } \\
\text { glass of water. }\end{array}$ & $\begin{array}{l}\text { TT1: Sitting down on } \\
\text { a chair. }\end{array}$ \\
\hline $\begin{array}{l}\text { MT2: Using staircase } \\
\text { from ground floor } \\
\text { to upper floor. }\end{array}$ & $\begin{array}{l}\text { PCT2: Sitting and } \\
\text { tying shoe lace. }\end{array}$ & BT2: Access to shower. & & $\begin{array}{l}\text { TT2: Standing up } \\
\text { from a chair. }\end{array}$ \\
\hline $\begin{array}{l}\text { MT3: Using staircase } \\
\text { from upper floor to } \\
\text { ground floor. }\end{array}$ & $\begin{array}{l}\text { PCT3: Reaching } \\
\text { lowest personal } \\
\text { care furniture unit } \\
\text { (drawer). }\end{array}$ & BT3: Access to toilet. & & TT3: Lying on a bed. \\
\hline $\begin{array}{l}\text { MT4: Walking from } \\
\text { entrance (lobby) } \\
\text { area to personal } \\
\text { suits. }\end{array}$ & $\begin{array}{l}\text { PCT4: Reaching } \\
\text { highest personal } \\
\text { care furniture unit } \\
\text { (drawer). }\end{array}$ & & & $\begin{array}{l}\text { TT4: Getting up from } \\
\text { a bed. }\end{array}$ \\
\hline
\end{tabular}

up the Good Work', 'Concentrate here', 'Low Priority' and 'Potential Overkill'. ${ }^{41}$

The second stage was persona creation. In this stage, an affinity diagram was considered to be useful method for analysing the qualitative and quantitative data gathered from the self-assessment questionnaire instrument. ${ }^{44}$ Through affinity diagramming, accessible BADL categories in a senior housing were obtained to define characteristic features when building personas. The affinity diagram mainly aims to elaborate on the scope of the problem and present it to the design team's focus with basic hierarchical diagramming. The question of how to organize the hierarchy of the obtained data is crucial for success. ${ }^{44}$ The affinity diagramming method for this study included the following seven steps: (i) consider the data from each participant and pull out key points (e.g., participant comments, observations, expectations, suggestions and design ideas); (ii) note each key issue individually on an index card; (iii) shuffle all the cards to avoid any pre-existing order and place each card on a wall inconveniently; (iv) group similar findings or concepts physically on the wall to identify themes in the data; (v) code the data with an open mind and structure the relationships emerges from the data without preconceiving; (vi) label the obtained data for each group; and (vii) consider the common issues within the comments and their relationship to one another. ${ }^{44}$ The third stage was the analysis of the simulation. Each task simulation (conducted by personas with and without GERT suit) was video recorded on video and measured in seconds. Later, the data was analysed statistically using ANOVA and $t$-test analysis to compare the number of variations within the personas as well as between the personas, depending on the suit condition.

The fourth stage was transferring the design knowledge gained through the analysis to a persona-based model. To develop the model and present knowledge, ontology framework was used. Ontology is the objective description of real-world things. Among the knowledge presentation strategies (by means of the computer), ontology is the most effective knowledge reusing and sharing strategy because it strongly guarantees the uniqueness and accuracy of the information. ${ }^{45}$ It is an abstract knowledge modelling, which treats knowledge as concepts, associated attributes and relations. Therefore, it is an explicit specification of conceptualization and a formal way to define the semantics of knowledge and data. ${ }^{46}$ In the context of ageing and design studies, ontology is mostly applied in pervasive computing and assisted living regarding older adults' housing environments, smart homes, sensor technologies and computerized cognitive rehabilitation. ${ }^{47}$ Most of the ontology studies have focused on monitoring data management issues. However, data formation and annotation of the knowledge domain in ontology-based approaches are more time consuming and require expertise, especially in designing systems for older adults. ${ }^{48}$ Because the efficiency of the knowledge support system determines the level of creativity and the quality of the design process, a suitable knowledge support system is crucial for designing older adults' housing built environments (those that promote healthy ageing). Therefore, the developed ontology should go beyond the specification of persona dimensions, visualization of ergonomics data or task analysis tools. A prioritized persona model could efficiently 
structure the BADL classes and make their relationships with related accessibility attributes clear. In this way, one could share information between software tools and overcome the unstructured nature of creating accessible senior housing environments for healthy ageing. Four main stages of the data analysis of this study are illustrated in Figure 2.

\section{Findings}

\section{Descriptive results}

All of the participants stated that they did not have any impairments or treatment processes (including orthopaedic, visual and audial impairments). However, two of the participants stated that they felt safer when using a walker even if they did not need a walker to walk independently. They mentioned that they especially felt the need to use a walker at night time when there were fewer people in the public areas. These two participants also stated that they felt safer and better when there was someone to assist them, especially when they were sleepy or ill. Forty-two among the 60 participants were very satisfied with the overall senior housing accessibility. Most of the female participants (28 of 32 participants) were very satisfied with accessibility within the senior housing, whereas most of the male participants were averagely dissatisfied (24 of 28 participants). Table 2 illustrates the socio-demographic characteristics of the participants.

Accessibility in senior housing was very important for most of the participants (47 of 60 participants) regardless of gender. Thirty-nine participants stated that accessibility in the bedroom was the most important element in senior housing. The second most important accessibility element in senior housing was the 'vertical circulation elements'. Regardless of gender, the participants (34 of 60 participants) who rated their independency level on BADL as 'very good' also rated accessibility in senior housing as 'very important'. There was also a statistically significant relationship between accessibility importance and independence level on BADL $(p=0.000)$. The study also collected the participants' ideas on accessible interior design. The ideas and suggestions related to the relationship between healthy ageing and accessibility were grouped through affinity diagramming within three main issues: safety, comfort and accessibility. Some of the exemplary quotations are illustrated in Figure 3.

\section{IPA categories}

IPA quadrants were constructed based on the twodimensional grid of importance and performance

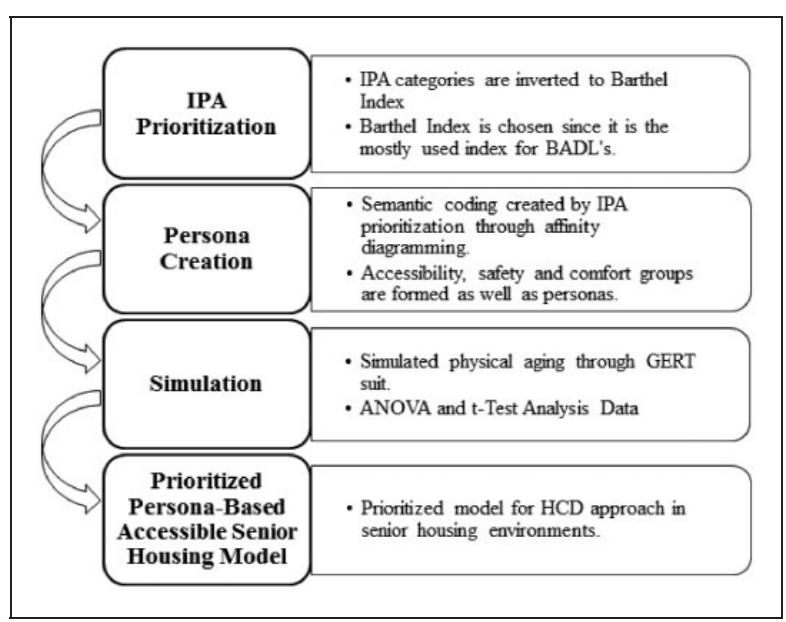

Figure 2. Procedure of the data analysis.

Table 2. Socio-demographic characteristics of the participants.

\begin{tabular}{lll}
\hline Characteristics & $\mathrm{N}$ & Percentage \\
\hline Gender & & \\
$\quad$ Female & 32 & 53.3 \\
$\quad$ Male & 28 & 46.7 \\
Age & & \\
$\quad 65-74$ & 0 & 0.0 \\
$75-84$ & 32 & 53.3 \\
$\quad 85+$ & 28 & 46.7 \\
Education & & \\
$\quad$ University Graduate & 60 & 100 \\
Marital Status & & \\
$\quad$ Single & 2 & 3.3 \\
$\quad$ Married & 2 & 3.3 \\
$\quad$ Divorced & 0 & 0.0 \\
$\quad$ Widow & 56 & 93.4 \\
\hline
\end{tabular}

ratings. Importance and performance ratings were used because IPA was chosen as the methodological tool, which set priorities on two dimensions of importance and performance. In the study, 13 items were removed because of the floor and ceiling effect. ${ }^{49}$ The means of overall importance and performance were the cut-off points between the IPA quadrants. Importance items are items that belong in Part $\mathrm{C}$ of the questionnaire instrument (symbolized with $\mathrm{C}$ and the related question number). Performance items are items that belong in Part D of the questionnaire instrument (symbolized with $\mathrm{D}$ and the related question number). Figure 4 illustrates the IPA graph with these four quadrants for this study.

According to IPA results, C7-D7, C15-D15 and C24-D24 are located in Quadrant 1, which means 'Keep up the Good Work'. These three items were 


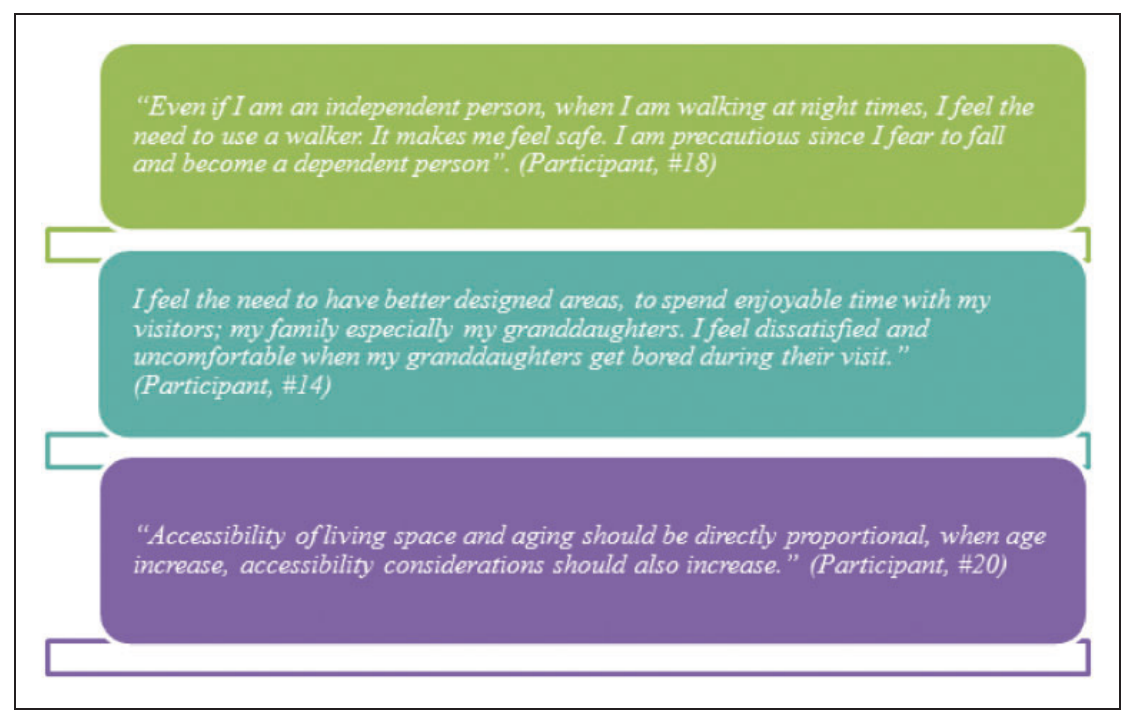

Figure 3. Exemplary quotations of participants.

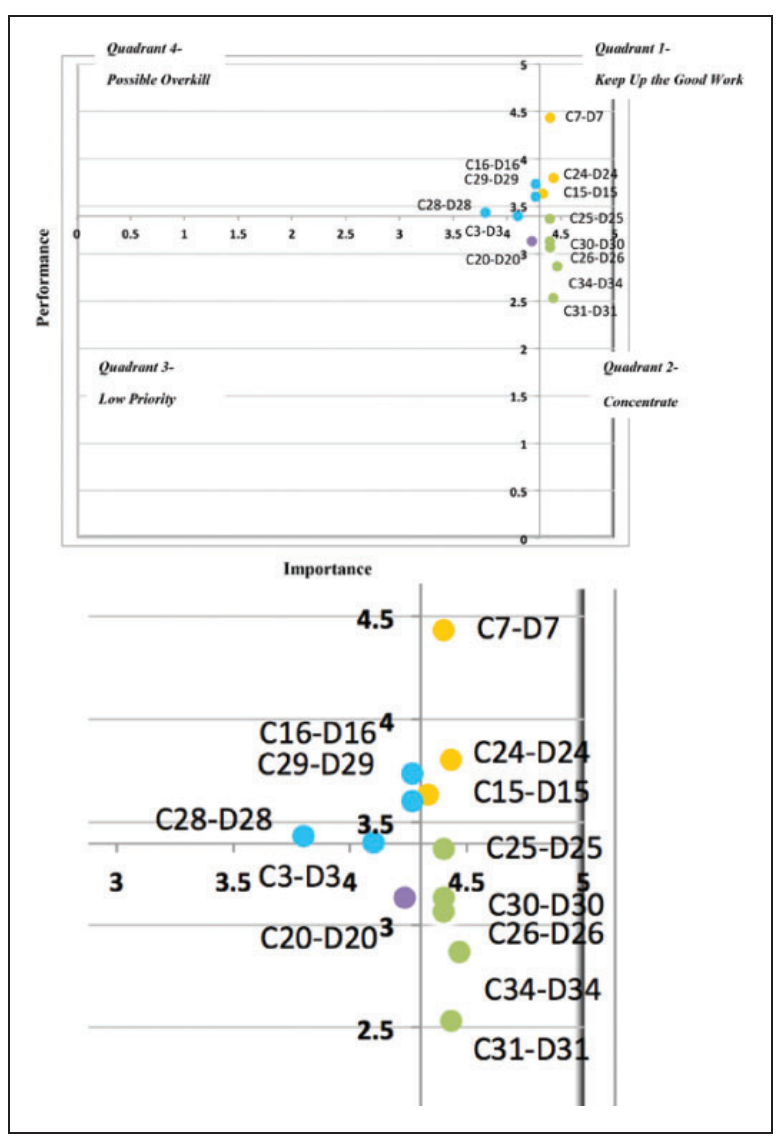

Figure 4. (a) Importance-performance analysis graph with the four quadrants; (b) a close-up view of the items.

satisfying to the residents of the senior housing; they are strong items and, together, the pillar of the organization. Because these three items are on the first quadrant, it means that they are important items for the residents of the senior housing. It also means that the participants are satisfied with their performance in regard to these three items. These three items were introduced to develop an understanding of the safety, legibility and flexibility issues in designing accessible circulation elements and handles of doors, cabinets and drawers. Senior residents considered it important that they were able to maintain certain degrees of comfort in their BADLs. The accessibility possibilities of the physical environment in senior housing could be referred to as 'satisfaction in performance'.

Quadrant 2 indicates low performance on important items. In Quadrant 2, 'Concentrate here', there are the following five items: C25-D25, C26-D26, C30-D30, C31-D31 and C34-D34. Designers should concentrate on these four items to enhance the accessibility performance of older adults. Ignoring these items could result in the failure of interior accessibility in senior housing design. The items in this quadrant emphasize the significance of dining activity. Compared to the other facilities, there was an urgent need in the critical analysis of approach, reach and manipulation in the dining hall. Moreover, to carry out the dressing activity, comfortable seating played a key role in the low accessibility performance of senior housing.

The items that fell into Quadrant 3, 'Low Priority', are not important and pose no threat to the organizations. In this study, only item C20-D20 was calculated in Quadrant 3. To maximize accessibility, outward opening bathroom doors could have low priority level compared to other accessibility attributes in senior housing. Such a priority categorization could indicate to build environment professionals how accessibility is addressed in relation to interior design. Deciding which attributes are not important could encourage designers 


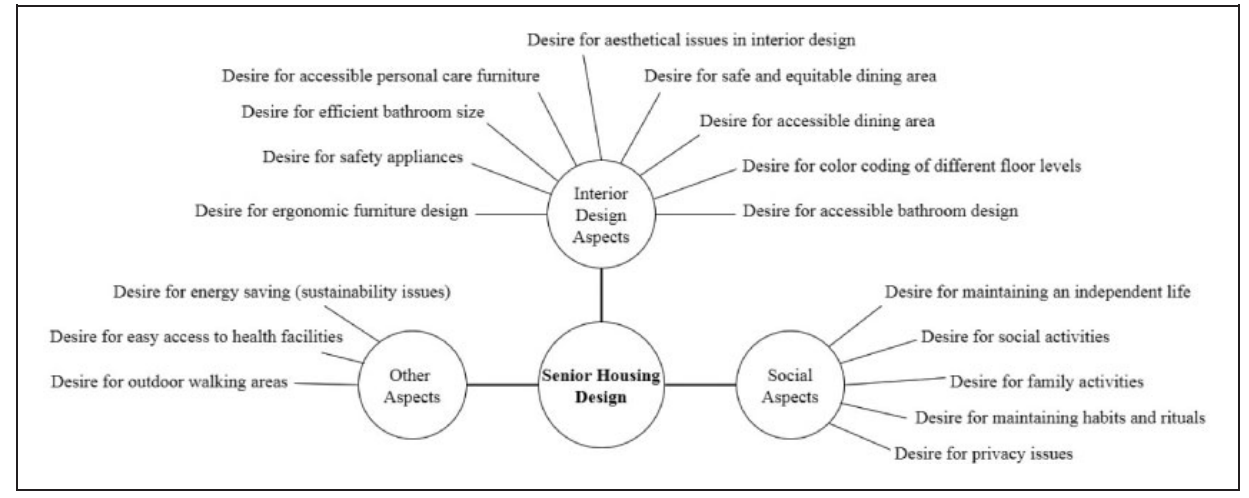

Figure 5. Overview of the categories and subcategories of factors affecting older adults' importance and performance criteria of a senior housing environment.

to go beyond minimum accessibility standards. Items C3-D3, C16-D16 and C29-D29 were calculated in Quadrant 4. Quadrant 4 means that there was 'Potential Overkill' in the items that were located in this quadrant after IPA analysis. It means that resources committed to these items would be better employed on other items. Thus, it was essential to decrease the priority level of these items. As mentioned, accessible interior design requires in-depth insight into attributes in order to put more emphasis on some attributes and/ or to eliminate them. By determining the attributes that are in the potential 'kill' quadrant, designers can possibly reconsider the misfit between what is really needed in practice to design accessible interiors and what is currently available in theoretical sources.

\section{Developed personas}

The study developed three personas by incorporating IPA graphs through the affinity diagramming method. The data gathered from the four parts of the selfassessment questionnaire instrument and the 13 items located in the IPA graph were grouped and listed with this diagramming method. User IPA insights were embedded into persona characteristics' definitions while conducting the process of persona creation and generating their BADL need profiles. User comments, ideas, observations and ranked IPA items were immersed into the structured groups. Each persona contained a selected set of IPA data relevant to their characteristic features. The affinity diagramming method for this study includes the following steps: (i) consider the data from each participant and pull out key points (e.g. participant comments, observations, expectations, suggestions and design ideas); (ii) note each key issue individually on an index card (such as participant number, task, or site related with the study); (iii) shuffle all the cards to avoid any preexisting order and place each card on a wall inconveniently; (iv) group similar concepts physically on the wall to identify themes in the data; (v) code the data with an open mind and without preconceived categories (the structure and relationship emerges from the data); (vi) label the obtained data for each group; and (vii) consider the common issues related with the obtained comments and their relationship between one another. This study, as a result of affinity diagramming, used six categories to define the characteristic features of building personas for the study. Figure 5 illustrates the overview of all the categories and subcategories of factors that affect older adults' importance and performance criteria of the senior housing environment.

According to affinity diagramming, there were the following six categories and their relevant attributes: (i) Safety - handle bars, seating unit and safe vertical circulation; (ii) Comfort - dining area furniture, personal care furniture, ergonomics of balcony and public area; (iii) Accessibility - appropriate size and space in the dining area, bathroom units, and legible routes as well as colour coding in way finding; (iv) Aesthetics furniture; (v) Socialization - independence, family times; and (vi) Privacy - respect for personal space and daily routines. These six categories were associated with IPA items, and three senior housing categories were finalized (Figure 6).

Later, three personas were created. Holistic persona consists of the following five aspects: (i) a persona should be realistic; (ii) a persona should include target user groups' personalities; (iii) a persona should include target user groups' intelligence; (iv) knowledge; and (v) cognitive process. ${ }^{49}$ This study also referred to these five key aspects of 'holistic personas' to eliminate the limitations related with the resemblance of real target users. These limitations in the study were dealt with as follows; by giving each persona a name to engage them in a deeply manner, by including information on their 


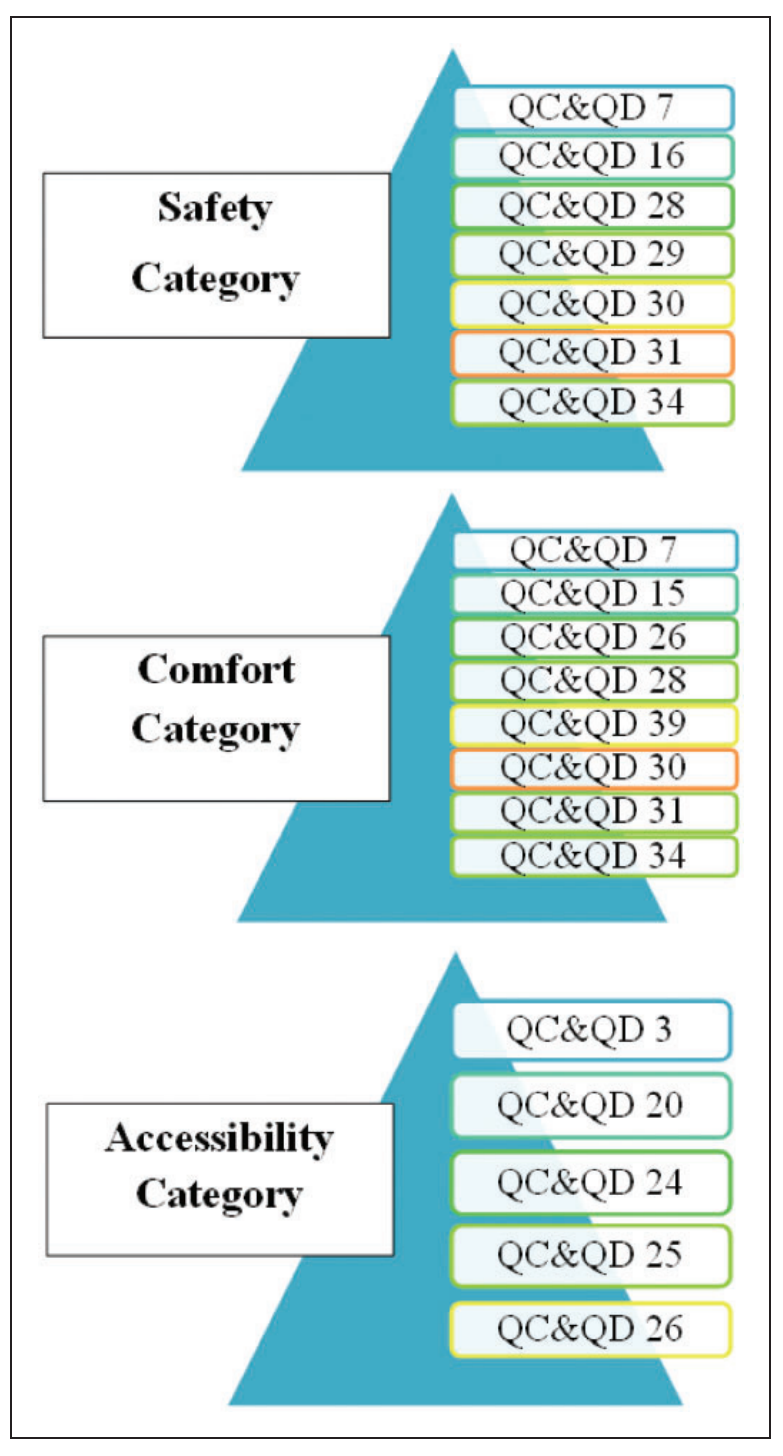

Figure 6. Three senior housing categories associated with importance-performance analysis items obtained through affinity diagramming.

importance-performance rankings, by structuring prioritized data using cluster analysis and affinity diagramming to represent a group of people with sufficient accuracy, and later by simulating to validate the reliability of the developed personas.

In this respect, each persona corresponded to each senior housing category, respectively: accessibility, safety and comfort. Figure 7 illustrates the personas with given names created for this study. Each persona was also shaped according to the reported age-related health problems that limited their physical activities, such as osteoporosis, postural problems and diabetes. In the study, one assumes that these health problems were not to a degree of affecting the independence of older adults in their BADL, because all the participants

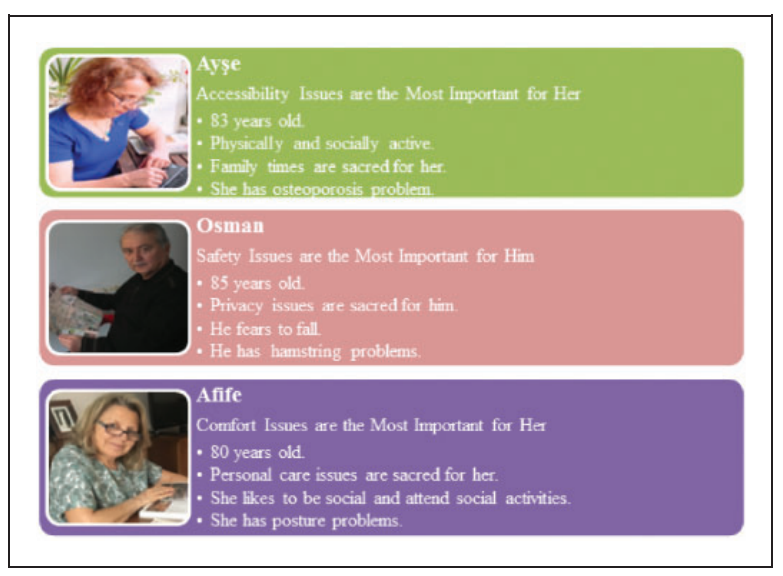

Figure 7. Personas of this study (Photographs of the personas are taken by the second author).

were independent according to the Barthel Index (as previously mentioned).

\section{Persona simulation with and without GERT suit}

Six interior architects conducted the five task scenarios presented in Table 1 in two session groups; a session with GERT suit and a session without GERT suit. To overcome the learning effect, there was a one-week break between the groups. To overcome the order effect, three randomly assigned evaluators conducted the task scenarios with GERT suit first, and later without GERT suit. The other three conducted the scenarios without GERT suit first and later with GERT suit. Each evaluator conducted the task scenarios separately to prevent any biases. Figure 8 illustrates the mean values of time duration in seconds for each persona and each task with and without the GERT suit.

ANOVA was conducted to test whether there were any significant differences between the session groups in terms of task effectiveness regarding the suit condition. ANOVA was conducted among three personas. According to the ANOVA results, there were significant time duration differences among personas, regardless of the suit condition and in the following three sub-tasks: (i) MT2 'Using staircase from ground floor to upper floor' regarding both conditions ( $p=0.005$ with GERT suit, $p=0.017$ without GERT suit); (ii) BT2 'Access to shower' regarding both conditions ( $p=0.015$ with GERT suit, $p=0.022$ without GERT suit); and (iii) TT4 'Getting up from bed' regarding both conditions ( $p=0.030$ with GERT suit, $p=0.035$ without GERT suit). The task effectiveness in only MT3, 'Using staircase from upper floor to ground floor', was significantly different in the GERT suit condition $(p=0.043)$. The study conducted post hoc 


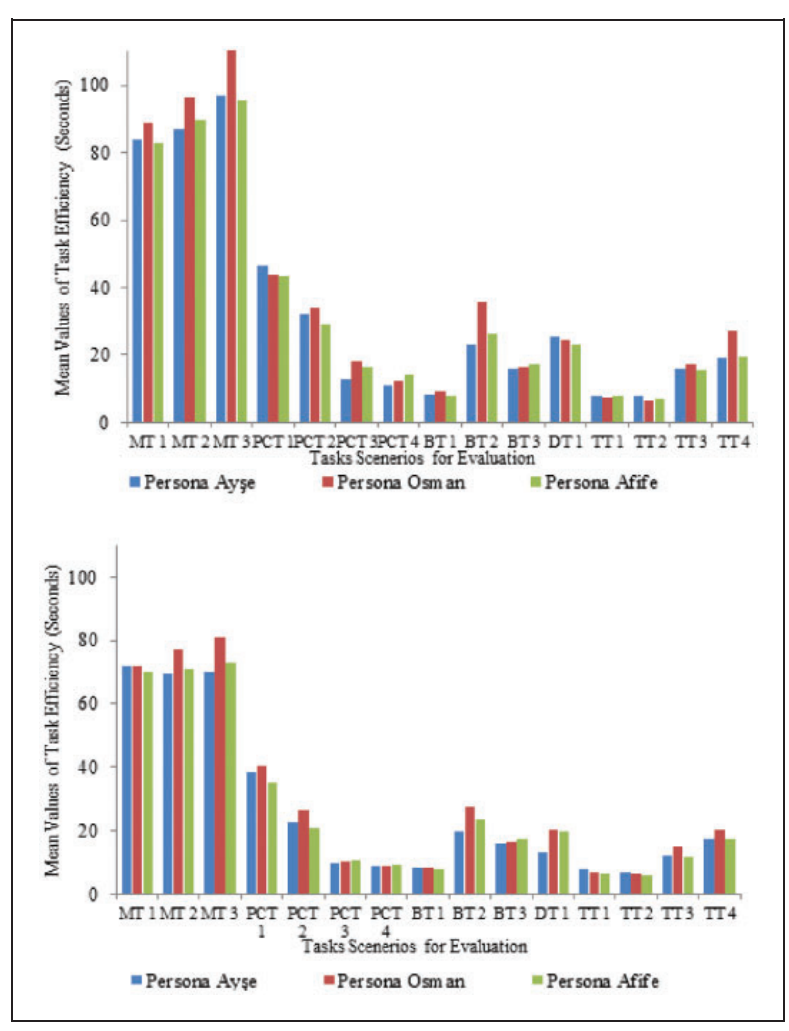

Figure 8. (a) Mean values of time duration in seconds for each persona and each task scenario with GERT suit and (b) without GERT suit.

comparisons, the Scheffe test, for these tasks to explore whether there were significant differences between the means of any two personas that were being compared. The Scheffe test was selected for post hoc comparison, because it examines subgroups formed by various combinations of the samples, rather than just pairwise comparisons. According to the Scheffe results, there were statistically significant differences between Ayşe and Osman and Afife and Osman considering the following sub-tasks: MT2, MT3, BT2 and TT4 (with significance value lower than 0.05 ).

An independent sample of $t$-test was also conducted to analyse the impact of the suit condition on the efficiency of the tasks. According to $t$-test analysis, when one considered the overall task efficiency, there were significant efficiency differences in terms of suit condition in all of the four tasks except the MT task: PCT 'Overall' $(F=0.890, t=1701, p=0.096$, at 0.05 level $)$; BT 'Overall' $(F=0.459, t=1.110, p=0.275$, at 0.05 level); DT overall 'Drinking a glass of water' $(F=0.005, t=1.670, p=0.126$, at 0.05 level $)$; and TT 'Overall' $(F=2.035, t=1,289, p=0.204$, at 0.05 level $)$. When one considered efficiency in the subtasks, the study found significant differences only in the following five sub-tasks: BT1 'Access to sink' $(F=3.769$, $t=1,754, p=0.110$, at 0.05 level); BT2 'Access to shower' $(F=1.567, t=1.685, p=0.123$, at 0.05 level $)$; TT1 'Sitting down on chair' $(F=1.706, t=1.387$, $p=0.196$, at 0.05 level); TT2 'Standing up from chair' $(F=2.168, t=1.265, p=0.235$, at 0.05 level $)$ : and TT4 'Getting up from bed' $(F=8.344, t=1.935, p=0.082$, at 0.05 level). Perceived closeness was also measured by the IOS Scale by Aron et al. ${ }^{39}$ According to the independent sample of $t$-test results, there was a significant perceived closeness difference between the groups with and without the suit $(p=0.000$, at the 0.05 level). The group with the GERT suit experienced higher perceived closeness toward older adults.

\section{Development of a PP-B model}

In the study, a PP-B senior housing environment model was developed based on an ontological framework. To our knowledge, this study is unique since ontologybased framework is not commonly used in designing for older adults' housing environments. In the ontology of this study, senior housing design categories are the three main domains of the framework: safety, comfort and accessibility. These domains were obtained by personas created according to IPA method's findings. In this framework, there are also three classes: 'senior housing environment', 'senior housing residents (users)' and 'BADL'. All these classes have subclasses with different object properties. For example, 'Grab bars are essential while transferring within interior spaces' is a general statement for an interior designer. The same transfer statement was also stated by KASEV residents during a survey questionnaire and observations as well, which was also presented in the framework with its related attributes. In the framework, arrows symbolize the relationships among different domains, classes and sub-classes. The relationship of 'senior housing environment' class is defined by 'need spaces of', which means that an accessible senior housing has the spaces described in the subclasses: entrance/lobby, bedroom (suits), bathrooms, etc. Moreover, the associations between the 'senior housing environment' class and the 'BADL' class are defined with the terms 'need spaces of' and 'need activities of', while the associations between 'senior housing environment' class and 'senior housing residents' are defined with the terms 'need consideration on' and 'need maintenance on'. As a result, for accessible senior housing, the study structured the multiple associations by 'spaces' class, 'activities' class and 'physical capabilities' class to find an optimum design solution. For assessing other accessible environment domains of older adults, associated classes, subclasses and accessibility categories could be gathered through an ontological framework, but a different PP-B model would be 


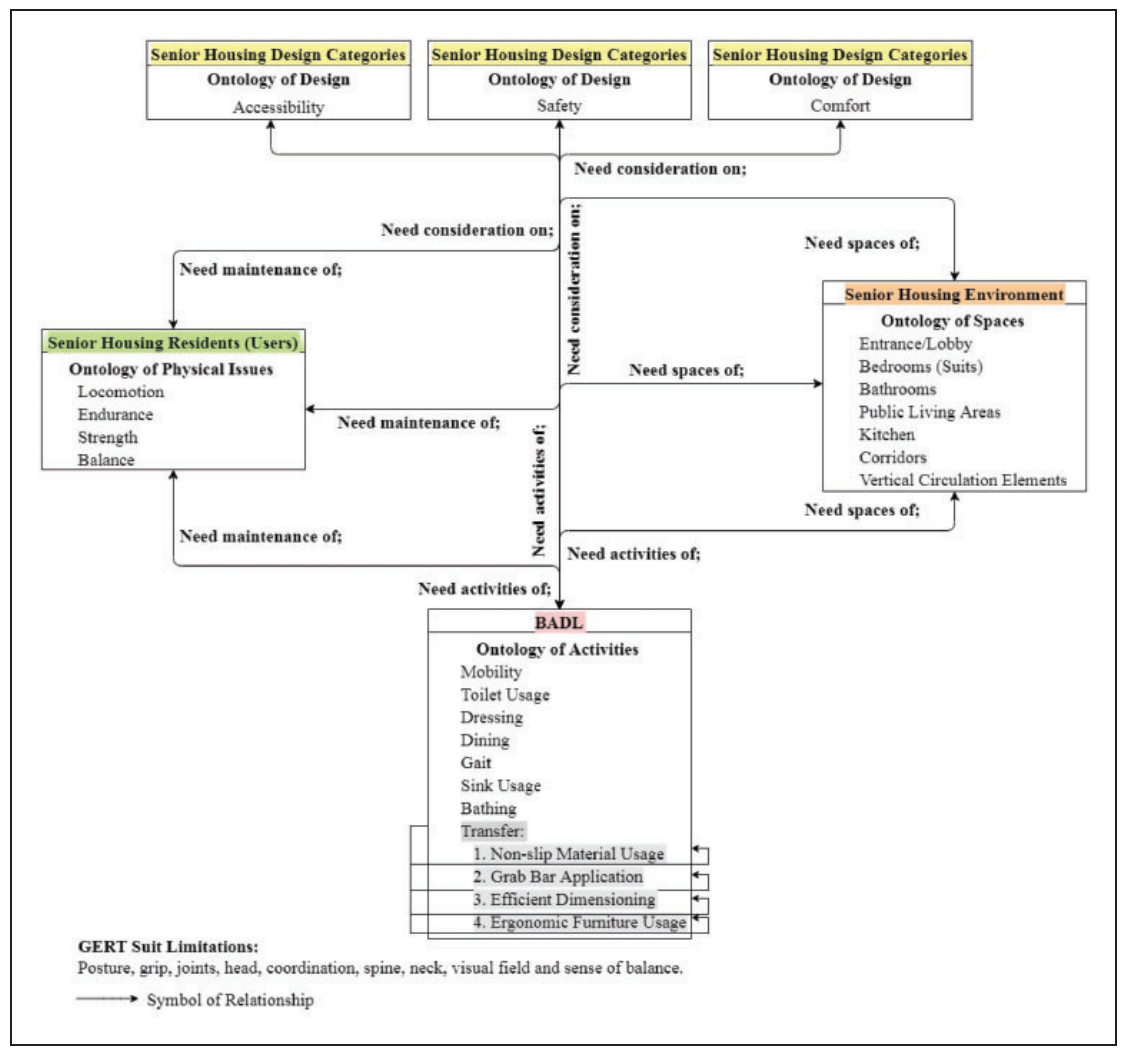

Figure 9. The PP-B senior housing environment model based on an ontological framework.

obtained with a different prioritized hierarchy. The accessibility knowledge network built upon ontologies would change if personas and activities changed. This network also corresponds with the iterative character of persona method, which is based on cyclic process composed of testing, analysing, designing, evaluating and revising the design based on the most recent iteration of domains and classes. Because the modelling for this study consisted of the real-life situations of older adults, we considered all extents related with senior housing design. Figure 9 illustrates the PP-B senior housing environment model based on an ontological framework.

\section{Discussion}

This study was an attempt to contribute to the existing scientific interior design literature by developing a new method of combining ageing simulation with personas through IPA and BADL. Even though the study presents a sequential design of the multi-method approach (IPA matrix and GERT ageing simulation) in which the GERT ageing simulation stemmed from the data gathered in the IPA process, it is crucial to state for the future studies of the interior design field that the two methods also operated in parallel as a kind of confirmation of each other. These types of combinations may also be useful to deal with the difficulties of stereotyping, which is a common difficulty experienced when gaining and applying knowledge about human beings and their interaction with their environments. The proposed combination with the simulations might have the potential to resolve an overgeneralized belief about users in terms of empathy/ engagement with personas. This is particularly relevant regarding stereotyping, which is often based on incorrect information. To follow the logical argumentation of the study and elaborate on this new method in detail, it is possible to discuss the findings from two points of view; (i) IPA and the Development of the Personas, and (ii) the ageing simulation suit as a test of simulated performance.

\section{IPA and the development of the personas}

A suitably designed physical environment is not only important in overcoming behavioural issues, but is also essential in providing comfort and promoting independence. ${ }^{50}$ In the study, IPA was an effective tool to describe accessibility attributes and optimize these attributes in order to maximize one's ability to access and carry out the designated BADL. Accessibility 
attributes in the literature often translate user needs into facts (such as minimum widths of corridors, etc.) and they offer limited data to interior designers. To go beyond accessibility attributes, the study proposed a persona development process based on data obtained by IPA. Although the persona creation process has been shown a significant role in this study and has helped resolve accessibility decisions in the senior housing context, one should question and carefully analyse the persona method as to whether it promotes standardization at the risk of hampering individualization (despite its cost effectiveness). The benefits of using persona could be limited if the information contain conflicts. Thus, to overcome this challenge, the study suggests the ageing simulation suit to be a test of simulated performance to construct later a hierarchical model composed of intermediary associations (as illustrated in Figure 8).

\section{The ageing simulation suit as a test of simulated performance}

The ageing simulation sessions in the study were developed as a test of simulated persona performance. The group with the ageing simulation suit experienced higher perceived closeness toward older adults. One should highlight that the study did not aim to verify the accessibility of senior housing by using the simulation suit; rather it aimed to overcome the limits of personas by increasing perceived closeness toward older adults (something designers tend to skip in the application of empathic design). Ageing simulation with the GERT suit and without the GERT suit provided insight as to how different personas may play a key role in addressing the different importance rankings of accessibility attributes and how individuals have different performance degrees in their BADL. For example, in the study not every older adult feels the need to use grab bars for support during transfer tasks/activities. According to the simulated performance of personas, the users who are giving importance to safety issues are the users who care about the availability of grab bars in an accessible senior housing design. It means that an accessibility attribute could be considered an essential design solution for some older adults while others do not consider grab bars as a crucial design issue. Moreover, the simulation findings of the study show that by wearing the suit, designers became aware of how they were affected by being old, even artificially, at the physical (bodily) level.

\section{Limitations and future study}

There were several limitations of the study. First, the study included a relatively small number of participants. As mentioned in the literature review, ageing is not a homogeneous process, and according to the WHO's (1998) categorization, there are three subgroups; young-old (65 to 74 years), middle-old (75-84) and oldest-old (85 years and more). So, the results could be different if there was a selection of age range to choose from in the suit design. Moreover, there are definitely other aspects of diversity, such as education, marital status and income level, etc. which play significant roles on user needs, demands and expectations while designing indoor and built environments. So, participants with different demographic data might present different IPA findings and a diverse ontological framework. Second, the cognitive capacities of older adults were not taken into consideration. However, as a result of the normal ageing process, physical capabilities decrease but cognitive capabilities reduced as well. In this manner, in order to conduct a more reliable study in terms of age limitations, cognitive capacities should be considered. Third, using representative older adults in addition to the younger designers during the ageing simulation sessions could give different design responses. With regards to the transferability of the PP-B model and quantitative personas to other user contexts, some limitations should be highlighted. In the health context, where a usercentric research is always essential while designing hospital indoors and built environments, direct participation of patients might be challenging because of some ethical concerns and time constraints. In the built environment contexts, such as airports, there might be more correlated parameters related to IPA attributes that require computation to transfer into persona profiles.

For future studies, the developed model with simulated physical ageing methodologies could be applied to other types of residential environments, such as cohousing environments. Cohousing is a community, composed of self-contained home units and these communities are enhanced by shared facilities and services. This new collaborative housing concept is designed to develop better healthcare facilities, services and social interactions for older adults. ${ }^{51}$ Since cohousing is one of the contemporary alternatives in senior housing environments, issues related to HCD for promoting healthy ageing should also be investigated in future studies. Moreover, enhancing the developed model with immersive virtual reality technologies would provide interactive design opportunities not only in buildings, but in product design as well. Furthermore, it should be noted that a PP-B model plays a key role in stimulating designers' engagement with user importance and performance attributes and translating the user insights into systematic diagrammatized quantified associations of design priorities. Since design practice 
differentiates itself from other formal disciplines, how to put personas and the proposed PP-B model in practice still requires further research. Interior designers and design students could work on automated design models assisted by semantic reasoning to synchronize user data elicited from personas combined with wearable simulations and to iterate multiple associations of indoor design attributes in prioritized models. The second author is working on the follow-up studies of the proposed model in airports and urban environments in terms of walkability attributes.

\section{Conclusion}

Creating accessible senior housing is a necessity of the contemporary design world. ${ }^{52}$ The representation of accessibility attributes, activities of older adults and their physical abilities require dealing with multiple instruments. Designing and decision-making while designing is a knowledge intensive process. ${ }^{53} \mathrm{~A}$ summary of the overall findings of the study is as follows:

1. The demonstrated PP-B model in the study can potentially provide a support mechanism for decisionmaking in older adults' housing design projects.

2. The model helps interior designers synchronize design knowledge on accessibility attributes and users' BADL performance along with their accessibility importance rankings. It is not possible to decide importance rankings of design attributes and define associations between attributes and performance degrees of activities in advance. What is possible to do is to develop critically importance-performance matrices that follow the next step of developing accessibility guidelines for specified environment contexts. By the help of PP-B model designers could capture the interactions between accessible design attributes and components for senior housing environment design.

3. The translation of the model into design guidelines is relevant in terms of leading interior designers on how to design a senior housing environment for healthy ageing.

4. The PP-B model could be implemented into an accessible design project in terms of informing the preparation of accessibility guidelines, which in turn would inform a design program for older adults. Implications of this model are significant because of the following reasons. First, the prioritization structure of the PP-B model has the potential to support individualized needs of personas. Second, the simulation structure of the model challenges existing accessibility standards and empathic models by making empathic approach active. Third, the ontological framework of the model could provide systematic user data and diagrammatized associations between activities and spaces.

5. Interior designers and built environment professionals are struggling to capture user data related to accessible design and structure its association with design requirements, because they require complex structured background knowledge processing. In this sense, this PP-B model also supports accessible design knowledge reasoning, retrieval, access and application during the complete process of housing environment design for older adults.

6. Additionally, the model has also relevance for studio instructors engaging students in design for older adults.

\section{Authors' contribution}

Ş MT contributed to the design of the study, data collection, data analysis and data findings as a part of her PhD Thesis at Bilkent University, in the Department of Interior Architecture and Environmental Design. YA contributed to the design of the study, paper writing and to the paper revision.

\section{Acknowledgements}

The authors would like to thank the study participants and acknowledge their contributions.

\section{Declaration of conflicting interests}

The author(s) declared no potential conflicts of interest with respect to the research, authorship, and/or publication of this article.

\section{Funding}

The author(s) disclosed receipt of the following financial support for the research, authorship, and/or publication of this article: The financial support for this study was supported by the grant of Science Academy's Young Scientist Award Program 2017 (BAGEP) received by the second author.

\section{ORCID iD}

Şevkiye Merve Taşoz (D) https://orcid.org/0000-0001-5213-5079

\section{References}

1. Junior RCF, Fernandes TG, Borges GF, Guerra RO and Abreu DCC. Factors associated with low levels of physical activity among elderly residents in a small urban area in the interior of the Brazilian Amazon. Arch Gerontol Geriatr 2018; 75: 37-43.

2. International Federation of Aging. The Rights of Older Persons, www.ifa-fiv.org/wpcontent/uploads/2016/03/Th eRightsOfOlderPersons_CollectionOfInternalDocument s.pdf (1990, accessed 4 March 2020).

3. An S, Lee Y and Kim JT. The effect of the public exercise environment on the physical activity for the active ageing of the elderly. Indoor Built Environ 2013; 22: 319-331.

4. Wang F, He P, Yuan C and Wang S. Isolated or integrated? Evaluation of ageing-friendly communities in Old 
Beijing City based on accessibility, social inclusion and equity. Indoor Built Environ 2020; 29: 465-479.

5. Bamzar R. Assessing the quality of the indoor environment of senior housing for a better mobility: a Swedish case study. J House Built Environ 2019; 34: 23-60.

6. World Health Organization. World report on aging and health, www.who.int/ageing/events/world-report-2015launch/en/ (2015, accessed 18 February, 2019).

7. King AC, Salvo D, Banda JA, Ahn DK, Chapman JE, Gill TM, Fielding RA, Demons J, Tudor-Locke C, Rosso A, Pahor M and Frank LD. Preserving older adults' routine outdoor activities in contrasting neighborhood environments through a physical activity intervention. Prev Med 2017; 96: 87-93.

8. Horgas AL, Wilms H and Baltes MM. Daily life in very old age: everyday activities as expression of successful living. Gerontologist 1998; 38: 556-568.

9. Calder A, Sole G and Mulligan H. The accessibility of fitness centers for people with disabilities: a systematic review. Disabil Health J 2018; 1: 1-18.

10. $\mathrm{Yu} \mathrm{C}$ and Lee Y. Housing requirements for an ageing society. Indoor Built Environ 2017; 26: 441-446.

11. Campbell NM. Designing retirement community third places: attributes impacting how well social spaces are liked and used. J Interior Des 2014; 39: 1-14.

12. Keates $\mathrm{S}$. Design for the value of inclusiveness. In: Van Den Hoven J, Vermaas PE and Van De Poel I (eds) Handbook of ethics, values, and technological design: Sources, theory, values and application domains. 1st ed. Amsterdam, Netherlands: Springer, 2015, pp.383-402.

13. Bianchin $\mathrm{M}$ and Heylinghen A. Just design. Des Stud 2018; 54: 1-22.

14. Huppert F. Designing for older users. In: Clarkson J, Keates $\mathrm{S}$, Coleman $\mathrm{R}$ and Lebbon $\mathrm{C}$ (eds) Inclusive design: Design for whole population. 1st ed. London: Springer, 2003, pp.30-50.

15. Evcil AN. Raising awareness about accessibility. Soc Behav Sci 2012; 47: 490-494.

16. Canadian Human Rights Commission. Performance Report, publications.gc.ca/collections/Collection/BT314-25-2006E.pdf (2006, accessed 8 October 2019).

17. Casserley $\mathrm{C}$ and Ormerod $\mathrm{M}$. The legal argument for inclusive design. In: Clarkson J, Keates S, Coleman R, Lebbon C (eds) Inclusive design: Design for whole population. 1st ed. London: Springer, 2003, pp.142-154.

18. Anvari F and Tran HM. Persona ontology for user centered design professionals. In: Proceedings of the 4th international conference on information management and evaluation: ICIME 2013, RMIT University Vietnam, Ho Chi Minh City, Vietnam,13-14 May 2013; pp.35-44. UK: Academic Conferences and Publishing International.

19. Cooper A. The inmates are running the asylum. Indianapolis, IN: SAMS, 1999.

20. Pruitt $\mathbf{J}$ and Adlin T. The persona life cycle: Keeping people in mind throughout product design. San Francisco: Morgan Kaufmann, 2006.

21. Grudin J and Pruitt J. Personas, Participatory Design and Product Development: An Infrastructure for
Engagement. In: Proceedings of the Participatory Design Conference, ACM Press, 2002, pp.144-161.

22. Miaskiewiez T and Kozar KA. Personas and user centered design: how can personas benefit product design processes. Des Stud 2011; 32: 417-430.

23. Personasv LN. In: Soegaard M and Dam RF (eds.) The Encyclopedia of Human-Computer Interaction, 2nd Ed. Aarhus, Denmark: The Interaction Design Foundation, 2012, www.interactiondesign.org/encyclopedia/personas. html (2012, accessed 4 June 2020).

24. Wilkinson CR and Angeli A. Applying user centered and participatory design approaches to commercial product development. Des Stud 2014; 35: 614-631.

25. Goodman-Deane J, Waller S, Demin D, Gonzalez-deHeredia A and Clarkson Pj BM. Evaluating Inclusivity Using Quantitative Personas. In: Design research society conference, Limerick, Ireland, 25-28 June 2018. Limerick: University of Limerick, 2018.

26. Iwarsson S. and Stahl A. Accessibility, usability and universal design- Positioning and definition of concepts describing person and environment relationships. Disabil Rehabil 2003; 25: 57-66.

27. Heylighen A, Van Der Linden V and Van Steenwinkel I. Ten questions concerning inclusive design of the built environment. Build Environ 2017; 114: 507-517.

28. Menec VH. The relation between everyday activities and successful aging: a 6-year longitudinal study. J Gerontol 2003; 58: 74-82.

29. Vermeulen J, Neyens JCL, Spreeuwenberg MD, Rossum E, Sipers W, Habets H, Hewson DJ and Witte LP. Usercentered development and testing of a monitoring system that provides feedback regarding physical functioning to elderly people. Patient Prefer Adhere 2013; 7: 843-854.

30. Postma CE, Zwartkruis-Pelgrim E and Du DE. J. Challenges of doing empathic design: experiences from industry. Int J Des 2012; 6: 59-70.

31. Pastalan LA. The empathic model: a methodological bridge between research and design. J Archit Educ 1977; 31: 14-15.

32. Cardoso C and Clarkson PJ. Simulation in user-centered design: helping designers to empathize with atypical users. J Eng Des 2012; 23: 1-23.

33. Lavalliere M, D'Ambrosio L, Gennis A, Burstein A, Godfrey KM, Waerstad H, Puleo RM, Laurenroth A and Coughlin JF. Walking a mile in another's shoes: the impact of wearing an Age Suit. Gerontol Geriatr Educ 2016; 38: 171-187.

34. Kullman K. Prototyping bodies: a post-phenomenology of wearable simulations. Des Stud 2016; 47: 73-90.

35. Mahoney FI and Barthel DW. A simple index of independence useful in scoring improvement in the rehabilitation of the chronically ill. Baltimore: Rehabilitation Section Baltimore City Medical Society, 1965.

36. Yesavage JA, Brink TL, Rose TL, Lum O, Huang V, Adey $\mathrm{M}$ and Leirer VO. Development and validation of geriatric depression screening scale: a preliminary report. J Psychiatr Res 1983; 17: 37-49.

37. Afacan Y. Extending the importance-performance analysis (IPA) approach to Turkish elderly people's self-rated 
home accessibility. J Hous and the Built Environ 2019; 34 : 619-642.

38. Zijlstra E, Hagedoorn $M$ and Krijnen WP. Van der Schans CP and Mobach MP. Route complexity and simulated physical ageing negatively influence wayfinding. Appl Ergon 2016; 56: 62-67.

39. Aron A, Aron EN and Smollan D. Inclusion of Other in the Self Scale and the structure of interpersonal closeness. J Pers Soc Psychol 1992; 63: 596-612.

40. Evans MR and Chon K. Formulating and evaluating tourism policy using importance-performance analysis. J Hosp Tour Res 1989; 13: 203-213.

41. Abalo J, Varela $\mathbf{J}$ and Manzano V. Importance values for importance performance analysis: a formula for spreading out values derived from preference rankings. $J$ Bus Res 2007; 60: 115-121.

42. Martilla JA and James JC. Importance-performance analysis. J Mark 1977; 41: 77-79.

43. Matzler K, Bailom F, Hinterhuber HH, Renzl B and Pichler J. The asymmetric relationship between attribute-level performance and overall customer satisfaction: a reconsideration of the importance-performance analysis. Ind Mark Manag 2004; 33: 271-277.

44. Holtzblatt K, Wendell JB and Wood S. Chapter 8: Building an affinity diagram. In: Holtzblatt $\mathrm{K}$ and Wendell JB WS (eds) Rapid contextual design: a how to guide to key techniques for user-centered design. 2nd ed. San Francisco: Elsevier, 2005, pp.159-178.

45. Studer R, Benjamins VR and Fensel D. Knowledge engineering: principles and methods. Data Knowl Eng 1998; 25: 161-197.

46. Chen $\mathrm{H}$ and Luo X. An automatic literature knowledge graph and reasoning network modeling framework based on ontology and natural language processing. Adv Eng Inform 2019; 42: 1-17.

47. Afacan Y and Sürer E. Modeling a user-oriented ontology on accessible homes for supporting activities of daily living (ADL) in healthy aging. In: GoodTechs' 19: Proceedings ACM Digital Library of the 5th EAI international conference on smart objects and technologies for social good, Politecnia de Universitat Valencia, Spain, 23-25 September 2019; pp.67-71.

48. Afacan Y and Demirkan H. An ontology-based universal design knowledge support system. Knowl-Based Syst 2011; 24: 530-541.

49. Tarrant A and Smith EK. The use of modified importance-performance framework to examine visitor satisfaction with attributes of outdoor recreation settings. Manag Leis 2002; 7: 69-82.

50. Cohen U and Weisman GD. Holding on to home: designing environments for people with dementia. 1st ed. Baltimore, MD: Johns Hopkins University Press, 1991.

51. Wang $\mathrm{J}$ and Hadjri $\mathrm{K}$. The Role of Co-housing in Building Sustainable Communities: Case studies from the UK. In: Environment-Behaviour Proceedings Journal. 3rd ABRA International Conference on Quality of Life, Kuching, Malaysia, 14 October-16 October 2017, pp. 255-265. UK: e-International Publishing House.

52. Van Hoof $\mathbf{J}$ and $\mathrm{Yu} \mathrm{CW}$. Ageing communities, supportive housing and enabling built environments. Indoor Built Environ 2020; 29: 295-298.

53. Sim SK and Duffy AHB. Towards ontology of generic engineering design activities. Res Eng Des 2003; 14: 200-223.

Appendix 1. Critical importance-performance ranking questions (Alternative 1).

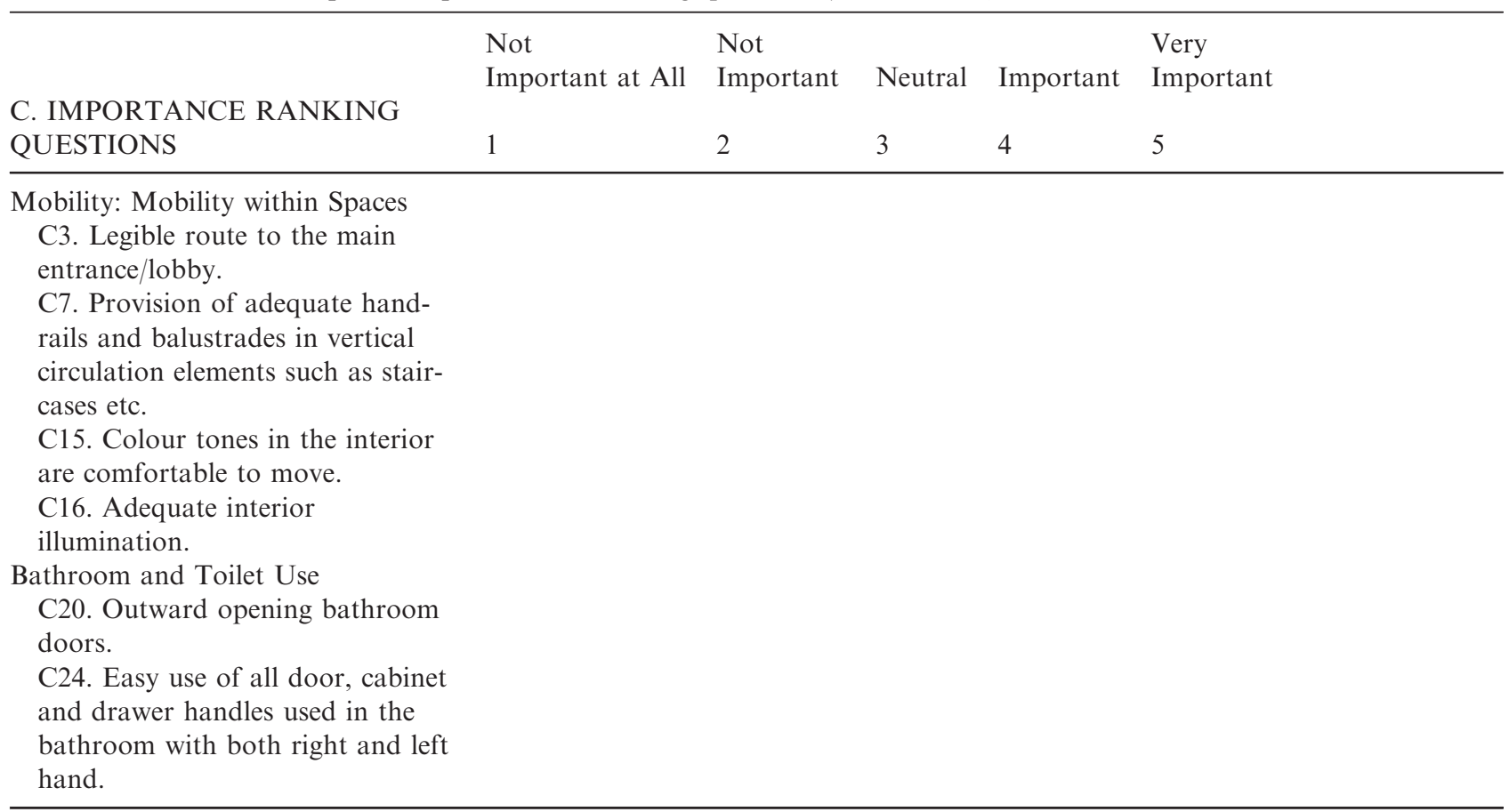


Appendix 1. Continued

\begin{tabular}{|c|c|c|c|c|c|}
\hline & $\begin{array}{l}\text { Not } \\
\text { Important at All }\end{array}$ & $\begin{array}{l}\text { Not } \\
\text { Important }\end{array}$ & Neutral & Important & $\begin{array}{l}\text { Very } \\
\text { Important }\end{array}$ \\
\hline $\begin{array}{l}\text { C. IMPORTANCE RANKING } \\
\text { QUESTIONS }\end{array}$ & 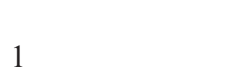 & 2 & 3 & 4 & 5 \\
\hline
\end{tabular}

Dining: Eating and Drinking

C25. Design of dining hall with appropriate space and dimensions. C26. Provision of a comfortable approach zone for dining tables. C28. Use of kitchen utensils with low physical effort.

Personal Care and Dressing C29. Bathroom mirrors at appropriate heights.

C30. Personal drawers and cupboards with low physical effort. C31. Design of comfortable seating area when dressing.

Transfer: Moving without Balance Lost C34. Ease of reach and access to furniture.

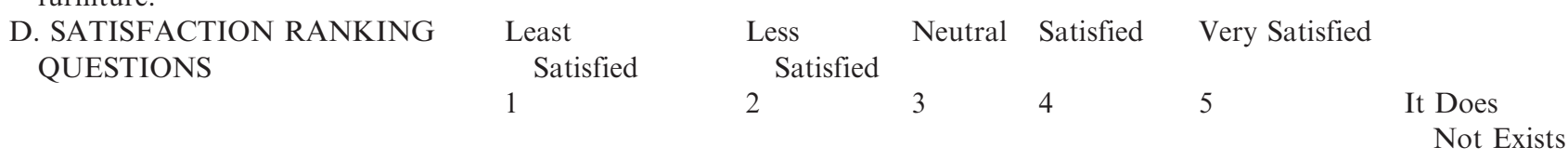

Mobility: Mobility within Spaces D3. Legible route to the main entrance/lobby.

D7. Provision of adequate handrails and balustrades in vertical circulation elements.

D15. Colour tones in the interior are comfortable to move D16. Adequate interior illumination.

Bathroom and Toilet Use D20. Outward opening bathroom doors.

D24. Easy use of all door, cabinet and drawer handles used in the bathroom with both right and left hand.

Dining: Eating and Drinking D25. Design of dining hall with appropriate space and dimensions. D26. Provision of a comfortable approach zone for dining tables. D28. Use of kitchen utensils with low physical effort.

Personal Care and Dressing D29. Bathroom mirrors at appropriate heights.

D30. Personal drawers and cupboards with low physical effort. D31. Design of comfortable seating area when dressing.

Transfer: Moving without Balance Lost D34. Ease of reach and access to furniture. 
Appendix 2. Critical importance-performance ranking questions (Alternative 2).

Mobility: Mobility within Spaces

C3-D3. Legible route to the main entrance/lobby.

C7-D7. Provision of adequate handrails and balustrades in vertical circulation elements such as staircases and elevators.

C15-D15. Colour tones in the interior are comfortable to move.

C16-D16. Adequate interior illumination.

Bathroom and Toilet Use

C20-D20 Outward opening bathroom doors.

C24-D24. Easy use of all door, cabinet and drawer handles used in the bathroom with both right and left hand.

Dining: Eating and Drinking

C25-D25. Design of dining hall with appropriate space and dimensions.

C26-D26. Provision of a comfortable approach zone for dining tables.

C28-D28. Use of kitchen utensils with low physical effort.

Personal Care and Dressing

C29-D29. Bathroom mirrors at appropriate heights.

C30-D30. Personal drawers and cupboards with low physical effort.

C31-D31. Design of comfortable seating area when dressing.

Transfer: Moving without Balance Lost

C34-D34. Ease of reach and access to furniture. 